\title{
Frontiers of Commercial Real Estate Portfolio Performance: Are Sector-Region Efficient Diversification Strategies a myth or reality?
}

\author{
Vitor Leone*1 and Geetha Ravishankar*2
}

\begin{abstract}
This paper departs from the traditional optimisation methods used to evaluate portfolio performance. Rather, the Stochastic Frontier Analysis approach is used to econometrically determine the benchmark real estate portfolio frontier and subsequently assess the gains from diversifying real estate portfolios along regional and sectoral dimensions in the UK. Portfolio specific inefficiency measures are obtained which indicate whether a portfolio is efficiently diversified and therefore places on the benchmark frontier and if not, the degree to which performance can be improved is quantified. Portfolio specific efficiencies average at 85\%-91\%, indicating scope to further improve performance. Further, diversification be it on a sectoral or regional dimension, contributes to significantly lower variability in portfolio efficiencies.

JEL classification: C13, G11
\end{abstract}

Key words: diversification, portfolios, performance, real estate, sector and regional effects

\section{Acknowledgements}

\footnotetext{
${ }^{1}$ Leicester Castle Business School, De Montfort University, Leicester, UK.

2 Corresponding author: Dr Geetha Ravishankar, Division of Economics, Nottingham Business School, Nottingham Trent University, NG14BU, Nottingham. New affiliation: Economics, Finance and Entrepreneurship Department, Aston University, Birmingham B47ET, email: g.ravishankar@aston.ac.uk.
} 
The authors thank Dr Peter Hayes, Managing Director Global Head of Investment Research PGIM Real Estate for generously providing the dataset used in this study. 


\section{Introduction}

Commercial real estate is an important asset class and according to Almond (2017) the global invested stock reached USD13.7tn by the end of 2015.This significant appetite for direct investment into commercial real estate was driven by institutional investors such as pension funds, insurance companies, REITS and open and closed ended funds with London continuing to attract the largest volume of investments worldwide.

Despite its importance, questions related to the performance of real portfolios based on the strategy and management adopted by investors remain. For example, how do the returnrisk features of different commercial properties (Industrial, retail and office) ${ }^{3}$ differ from one another and how can investors explore the differences in order to maximise the portfolio diversification process and consequently performance? Crucially, are these investors being effective in defining the efficient frontier of their real estate portfolios?

Conventionally, the portfolio selection problem has been examined using the meanvariance analysis concept from the Modern Portfolio Theory (MPT). MPT was proposed by Markowitz (1952) who theorised the portfolio construction process by defining the efficient frontier of risky assets. When applying MPT, the problem can be formulated as an optimisation task in which the risk is minimised subject to some return and weight constraints. The risk is quantified by the variance of the portfolio returns. Thus, portfolios that maximise returns for given levels of risk form the benchmark efficient frontier and deviations from this benchmark suggest the existence of inefficiencies and scope to further increase returns at given risk levels or lower risks for given returns.

This discussion of constructing a well-diversified commercial real estate portfolio and its theoretical benchmark whatever the approach chosen (sector, region, and property specific

\footnotetext{
${ }^{3}$ A detailed analysis of the time-series features of the UK commercial property returns can be found at Coleman and Leone (2015).
} 
variables) is of considerable importance. However, one important matter is rarely mentioned in this debate: once the diversification strategy is defined, are these portfolios really located on the efficient frontier? If not, what is the resulting level of underperformance?

The aim of this research is to assess portfolio efficiency under differing diversification strategies by adapting the Sharpe Ratio performance measure for use with the Stochastic Frontier Analysis (SFA) approach. SFA is used to econometrically identify the benchmark real estate portfolio mean-variance frontier. In doing so, it draws on the work of Hu et al. (2013) who undertake an evaluation of mutual fund performance by applying the SFA method to a generalised reward-to-volatility measure (Sharpe Ratio).

Originating in microeconomic production theory and developed independently by Aigner et al. (1977) and Meeusen and van den Broeck (1977), SFA identifies a production function with a composed error term that disentangles inefficiency effects from random disturbances. The inefficiency component is generated by factors within the firm's control and when present, places the firm below its benchmark frontier. The random disturbance element, in turn, generates a frontier that is stochastic in nature. Transposing this to a meanvariance frontier setting, the error term in SFA has the following components - a normally distributed residual to capture stochastic noise and a non-negative, one-sided distribution to isolate and quantify the degree to which a given portfolio deviates from the benchmark efficient frontier.

The advantages to this approach are threefold. First, it econometrically determines the mean-variance frontier thereby allowing for an assessment of its statistical properties. The approach can also be readily extended to incorporate additional factors (e.g. diversification strategy adopted, sector, region or a mix of both) that impact the return profile of the portfolios under evaluation. Secondly, the returns are generated in a stochastic environment. Finally, it yields portfolio-specific measures of deviation from the benchmark frontier. These 
portfolio-specific measures of (in) efficiency indicate not only if a portfolio is efficiently diversified and therefore places on the benchmark frontier but if not, the degree to which performance can be improved. The (in) efficiency measures, in turn, can be linked to portfolio characteristics to determine the source of the deviation from the frontier. To our knowledge, the use of SFA in assessing the performance of commercial real estate portfolios is undertaken for the first time in this paper.

The econometric SFA method adopted in this paper, thus contrasts with the nonparametric and deterministic approaches of traditional mean-variance approaches to portfolio construction and evaluation. The latter methods preclude an assessment of the statistical properties of the mean-variance frontiers. Results from such statistical evaluations would offer compelling evidence that the identified boundary of the mean-variance space does indeed form a benchmark mean-variance frontier. Further, while failure to reside on the mean-variance frontier is symptomatic of sub-optimal portfolio performance, a portfoliospecific measure of the degree of such under-performance is not obtained.

The SFA method is deployed on portfolios initially anchored in the UK Office, Retail and Industry real estate segments. These are, subsequently, diversified across the London, South-east and the Rest of the UK regions and the Office, Retail and Industrial Sectors. The findings indicate that the average realised portfolio specific efficiencies were approx. $90 \%$ indicating scope to further improve performance.

The contribution of this study is, thus, threefold: (i) it contributes to the literature on sector-region diversification strategies; (ii) it presents a method that allows the investor to determine (whatever strategy adopted) a benchmark frontier and assess its efficiency and performance and (iii) SFA may address a well-known problem in portfolio theory of what benchmark to use by creating a theoretical econometric efficiency frontier. 
The remainder of this paper is organised as follows. Section 2 reviews the extant literature on real estate portfolio diversification. The methodology, data and sources used are presented in Sections 3 and 4. Section 5 presents the results with a discussion of the same. Finally, Section 6 concludes the paper with a review of the main findings.

\section{Literature Review}

Our paper relates to several strands of the extant literature on UK commercial real estate portfolios with particular interest in determining the efficacy of sectoral and regional diversification strategies.

Utilising the MPT framework Eichholz et al. (1995) find that the magnitude of gains from regional diversification in the UK is variable and displayed an increasing trend the further the region was from London. Gains relating to property type diversification were found to be greatest for the Industrial and Office markets. The authors conclude that diversification was optimised over the North and South regions or just the London market.

Lee and Byrne (1998) extend the research on sector-region diversification by incorporating three super-regions and economic regions based on travel-to-work areas in addition to the standard administrative UK regions. Interestingly, in some instances, functional groups were found to offer a superior diversification profile.

Similar results are found in Byrne and Lee (2000). The authors further highlight that the largest percentage reduction in total risk, from naïve diversification occurs within the regional portfolios spread across the retail, office and industrial sectors. They conclude that two properties in the same sector, but in different regions, are closer substitutes than two different property types in the same region thus supporting regional diversification strategies.

Lee and Stevenson (2005) investigate the incremental contribution provided by sector and regional diversification in enhancing the risk/return profile of a real estate portfolio initially heavily concentrated in London. Their findings suggest that concentrating portfolios 
in a single sector and region results in a sub-optimal diversification strategy while a diversification strategy either across property types in London or across regions within a sector provided significant performance gains.

Departing from the traditional mean variance analysis, Byrne and Lee (2011) assess sector versus regional diversification within the UK using mean absolute deviation (MAD) portfolio optimisation and functional classifications by retesting the proposition that such groupings may offer superior diversification benefits. The findings echo the extant literature, with sectors superior to regions.

Following Brandt et al. (2009), Plazzi et al. (2011) use a given property’s cap rate, size and vacancy rate as conditioning variables to the allocation of commercial real estate portfolios in the USA. In relation to economic conditions, the findings indicate a variation in optimal portfolios over expansion and recession periods. The general conclusion is that investors can enhance the risk-adjusted performance of their portfolios by explicitly considering property features.

The evidence so far suggests that, property type dominates geographical diversification. Nevertheless, one likely drawback of these studies is the lack of assessment of the degree to which a sectoral diversification strategy produces portfolios that are biased towards one type of commercial property or regional clustering.

Thus, Cullen (1993), using cluster analysis techniques finds that industrial property is relatively homogenous across the UK. Hoesli, et al. (1997) and Hamelink, et al. (2000) find similar results to those of Cullen (1993) in that there appears to be a geographical dimension to the office and industrial property types, with the City office market in particular differing from the Southeast and the rest of the UK. The industrial property sector clustered in London, its periphery and other peripheral markets. The retail property markets, however, clustered into a single group without a London bias. This is not a surprise as Coleman and Leone 
(2015) find, when investigating regime shifts in the UK commercial property returns, the industrial sector returns are more stable.

Evidence of spatial concentration in investor behaviour in the UK is provided by Byrne and Lee (2006, 2009, and 2010). They find that institutional office investment is concentrated in very few areas (e.g. City of London), again distinguished by their size and also employment profile (Byrne and Lee, 2006); retail holdings are notably more geographically diffuse, but correlate with the urban hierarchy to focus on urban areas with large and dense populations with a greater stock of property (Byrne and Lee, 2009) and finally investment in the industrial property sector is less dispersed than retail, concentrating traditionally on areas with high levels of manual employment but more recently also on the distributional (logistic) sector, for which location and accessibility is a principal consideration (Byrne and Lee, 2010). This bias, originated by spatial concentration, may generate a level of underperformance of these portfolios and an assessment of this inefficiency is needed to be explored.

Jackson (2013) re-visits the debate regarding optimal risk diversification strategies in the direct real estate sector by examining and comparing the possibilities provided by the classifications of local markets developed by Hamelink et al. (2000) with those of Jackson (2002) and Jackson and White (2005a, 2005b) additionally comparing those to the regional and sectoral classifications. The results suggest that, although the benchmark portfolios are below the efficient frontiers in periods of relative stability but that the differences are not statistically significant. Conversely, during periods of volatility and heterogeneity in local market performance, the benchmark portfolios are below the lower confidence limits for the efficient frontiers and/or are positioned at the highest risk levels (for low returns).

One likely reason for underperformance might be related to the benchmarking process adopted for monitoring performance within investment strategy, goals and objectives. Byrne 
et al. (2013) argue that benchmarking provides a reference point for the assessment of investment performance, however as already mentioned, the UK investors’ spatially concentrated behaviour may result in benchmarks that are not based on economic rationale looking for utility maximisation but based on facts other than views and believes of the peers (herding behaviour). Byrne et al. (2013) states that the targeting markets by investors far outweighs the levels of investment supported by rationality based on key markets fundamentals, suggesting that herding may be present. Thus, if the benchmark is not appropriate to be used for portfolio performance measure the construction of efficient frontiers may be flawed.

The aforementioned literature either do not examine if portfolios are really located on the efficient frontier or provide a measure of inefficiency.

\section{Method}

By combining assets that vary in their response to economic fundamentals, an increase in returns for given levels of risk or, equivalently, a reduction in risk for given returns, may be achieved. In determining the extent to which such gains can be realised, the performance evaluation exercise, thus, typically centres on an analysis of the risk-return profile of various portfolios. Portfolios that maximise the returns for given levels of risk form the benchmark efficient frontier and the associated diversification strategies are preferred. The mean-variance frontier is therefore formed of portfolios for which no other portfolios offer the same expected returns and smaller risk. Deviations from this benchmark imply the existence of inefficiencies and evidence scope to further increase returns at given risk levels or lower risks for given returns.

Although MPT is used across alternative and distinct asset classes to guide portfolio construction including direct property, this type of asset class deviates from the classical assumptions required by Markowitz to estimate the structure of the optimum efficient frontier 
for any given risk-return utility. This deviation suggests that direct property violates the assumptions underlying portfolio theory as it is characterised by heterogeneous stock, often not widely or publicly available information, large lot sizes, indivisibility, high transaction costs and illiquidity (Hoesli and MacGregor, 2000; Byrne et al., 2013). A likely consequence of these features of direct property is the possibility of the MPT analysis failing to generate real estate portfolios located on the efficient frontier and consequently undermining their performance.

The empirical analysis adopted in this paper assesses such portfolio performance under differing diversification strategies by adapting the Sharpe ratio performance measure for use with the Stochastic Frontier Analysis (SFA) approach, which is used to econometrically identify the benchmark mean-variance frontier. In doing so, it draws on the work of Hu et al. (2013) who undertake an assessment of mutual fund performance by applying the SFA method to a generalised Sharpe ratio. In fact, while SFA is widely used in the assessment of mutual fund performance (Annaert et al., 2003; Santos et al, 2005.; Hu et al., 2013), to our knowledge its use in evaluating the performance of real estate portfolios is undertaken for the first time in this paper.

SFA uses a composed error term to disentangle inefficiency effects from random disturbances. The inefficiency component when present, places the portfolio below its benchmark frontier. The random disturbance element, in turn, generates a frontier that is stochastic in nature.

The primary advantage of using this approach to assess portfolio performance is that portfolio specific inefficiency measures are obtained which indicate not only if a portfolio is efficiently diversified and therefore places on the frontier but if not, the degree to which performance can be improved. In other words, portfolio specific (in) efficiency values can be obtained. Jackson (2013) finds evidence of benchmark portfolios below a mean-variance 
optimal portfolio but does not provide the level of underperformance attached to these portfolios. Two further advantages are derived from using the SFA method to determine the benchmark frontier. The first is revealed when examining the nature of the mean variance frontier as determined using Ordinary Least Square (OLS) regressions as in Fisher and Liang (2000), Andrew et al. (2003) and Heston and Rouwenhorst (1994). The frontier thus determined is based on average relationships unlike one determined by SFA. Secondly, the SFA method explicitly recognises and distinguishes between statistical noise and inefficiency, both of which impact the ability to generate excess returns at given risk levels.

$$
\begin{aligned}
& R_{i t}-R_{f t}=f\left(X_{i t}, Z_{i t}\right)+\varepsilon_{i t} \\
& \text { where }: \varepsilon_{i t}=v_{i t}-u_{i t}
\end{aligned}
$$

In equation [1], the excess returns of portfolio $i$ in period $t$ is thus a function of the input variables $X_{i t}$ and control variables $Z_{i t}$. Following Hu et al. (2013), equation [1] takes the form of a standard Sharpe ratio, ranging from $0-1$, when the standard deviation of portfolio returns forms the sole input. The error term in the SFA framework is comprised of the usual randomly distributed error term $v_{i t}$ and a non-negative inefficiency variable, $u_{i t}$. The former is independently and identically distributed as $N\left(0, \sigma_{v}^{2}\right)$ while the latter follows a halfnormal distribution, i.e. $N^{+}\left(0, \sigma_{u}^{2}\right)$.

The validity of applying the SFA approach is assessed through two tests based on OLS residuals. As noted by Kumbhakar and Lovell (2000), the error term in an SFA model is defined as $v_{i}-u_{i}$ where the inefficiency element, $u_{i} \geq 0$ and the random error term, $v_{i}$ is normally distributed with mean zero. The equivalent OLS specification should, therefore, display a negative skewness in its residuals. Thus, if negative skewness is detected in the OLS residuals, the null hypothesis of no skewness can be rejected. This would support the application of an SFA model. 
A further test for the presence of inefficiency is provided by Coelli (1995) and is based on the third moment of the OLS residuals which is asymptotically normally distributed. When significant, the null hypothesis of no skewness in the OLS residuals can be rejected. Specifically, the presence of inefficiency is indicated by a negative skewness, itself evidenced by $m_{3}<0$. Coelli (1995) suggests that a test of $m_{3} \geq 0$ is appropriate when a null of zero skewness is assumed for the errors. The test statistic is obtained as $m_{3} /\left(6 m_{3} / I\right)^{1 / 2}$ and is asymptotically distributed as $N(0,1)$.

The absence of inefficiency effects is also assessed using a generalised Likelihood Ratio (LR) test wherein the log likelihood functions of the restricted and unrestricted models are evaluated. The following test statistic is used:

$$
L R=-2\left[\ln L_{R}-\ln L_{U}\right] \sim \chi^{2}(J)
$$

where $\ln L_{U R}$ and $\ln L_{R}$ are the maximised values of the unrestricted and the restricted $\log$ likelihood functions. These unrestricted and restricted models are, respectively, the SFA model and its OLS counterpart. $J$ represents the number of restrictions. The null hypothesis is one wherein there is no one-sided error term, i.e. the LR test assesses the presence of $u_{i}$. The critical values for the test statistic in [2], which is asymptotically distributed as mixture of chi-squared $\chi^{2}$ distributions (Coelli, 1995), is obtained from Kodde and Palme (1986).

Following Battese and Coelli (1988), portfolio specific efficiencies are obtained as $E\left[\exp \left(-u_{i}\right) \mid \varepsilon_{i}\right]$, which ranges between zero and unity. A value of unity signifies an absence of inefficiency and places the portfolio on the benchmark frontier. SFA thus yields a relative performance measure wherein portfolios that offer the highest return for the given level of risk are placed on the frontier while those that diverge from the frontier possess scope to generate further returns at the given risk level. Maximum Likelihood Estimation (MLE) is used to operationalise this approach and obtain relevant parameter values. 
The basic (homoscedastic) empirical SFA specification adopted to operationalise the above is:

$$
\begin{aligned}
R_{i t}= & \alpha_{0}+\sum_{i=1}^{I} \beta_{1} \ln \text { Std } \_\operatorname{Dev}_{i t}+\sum_{i=1}^{I} \beta_{2} \operatorname{Div}_{i}+\beta_{3} \text { Trend }+\beta_{4} \text { Peak }+\beta_{5} \text { Trough } \\
& u_{i t}-v_{i t}
\end{aligned}
$$

where $\quad R_{i t}=$ excess returns of portfolio $i$ in period $t, i=1 \ldots I ; t=1 \ldots T$

$\ln S t d \_D e v_{i t}=$ risk associated with property $i$ in period $t$

$\operatorname{Div}_{i}=$ Dummy variable reflecting diversification strategy relative

to undiversified ; $\quad i=1 \ldots I$

Trend $=$ Time trend variable

$u_{i t}=$ non-negative, portfolio-specific inefficiency term;

$$
u_{i t} \sim N+\left(0, \sigma_{u}^{2}\right)
$$

$v_{i t}=$ random error term; $N\left(0, \sigma_{v}^{2}\right)$

Dummy variables are used in equation [3] to represent regionally diversified and sectorally diversified portfolios. As such, the ability of such a strategy to generate significant excess returns relative to an undiversified portfolios can be evaluated. A time trend variable, Trend, is included to account for shifts in the frontier over time. Finally, a dummy variable, Peaks and Troughs, is included to account for market peaks and troughs, relative to a base of normal market performance.

To determine if departures from the frontier are systematically related to the diversification strategy adopted, we follow Hadri (1999) and Hadri et al (2003) ${ }^{4}$. Thus,

\footnotetext{
${ }^{4}$ An alternative approach, in the form of the Battese and Coelli (1995) SFA model, specifies the mean of inefficiency as a function of determinant variables. This requires a truncated normal distribution for the inefficiency term. Maximum likelihood estimations for this specification failed to converge.
} 
$u_{i t} \sim N^{+}\left(0, \sigma_{u i t}^{2}\right)$ and $\sigma_{u i t}^{2}=\exp \left(z_{i t}, \delta\right)$. The variance of inefficiency is therefore a function of determinants, $z_{i t}$. In addition, $v_{i t}=N\left(0, \sigma_{v i t}^{2}\right)$ and $\sigma_{v i t}^{2}=\exp \left(h_{i t}, \varphi\right)$. This specification thus has the added advantage of handling heteroscedasticity in the error and inefficiency terms ${ }^{5}$, the presence of which is confirmed using likelihood ratio tests following Hadri et al (2003).

The aforementioned specification also possesses a scaling property (i.e., specifying the distribution of $u_{i t}$ as $N^{+}\left[\left(0, z_{i t} \delta\right)\right]$ or $\left.\sigma_{u i t}=\exp \left(z_{i t}, \delta\right) * N^{+}(0,1)\right)$ whereby changes in $z_{i t}$ change the scale but not the distribution of $u_{i t}$. As noted by Alvarez et al (2006), this possesses an interesting economic interpretation, viz., $u_{i t}$ is the base inefficiency level of the portfolio reflecting management skills while the degree to which such skills are successfully deployed to attain efficient performance depends on factors represented by $z_{i t}$.

Finally, to verify that the results obtained are not unique to the distributional assumptions made under the SFA model (i.e. normally distributed random error component and a half-normally distributed inefficiency component), all estimations are additionally carried out assuming an alternative exponential distribution for the technical inefficiency component. Relative parameter and portfolio efficiency stability would signify robust results.

\section{Data}

The quarterly data used in this study are sourced from the MSCI IPD-UK database which retains information on property returns, disaggregated by regions and sectors in the UK. MSCI's IPD UK Monthly Property Index measures unlevered total returns of directly held standing property investments from one valuation to the next. The index tracks

\footnotetext{
${ }^{5}$ As noted by Kumbhakar and Lovell (2000), heteroscedasticity in the random error yields consistent estimates of the frontier parameters with the exception of the intercept. However, the resulting efficiency estimates are biased. Heteroscedasticity in the inefficiency component biases both the frontier parameter and the inefficiency estimates.
} 
performance of 3,341 property investments, with a total capital value of GBP 47 billion as at July 2016 . The market coverage is estimated to be $10.5 \%$ of the professionally managed real estate investment universe with results back to 1987 . The breakdown of the Index can be seen in Table 1.

\section{[Insert Table 1]}

The data spans from 1987:Q1 to 2016:Q1 . In order to assess the degree to which SFA identifies inefficient portfolios, the total returns from the Office, Retail and Industry sectors across London, the South-East and the Rest of the UK are used. The total return includes monthly capital appreciation, net of capital expenditure ${ }^{6}$, plus monthly net income ${ }^{7}$ received expressed as a percentage of monthly capital employed. Quarterly returns are computed by compounding the returns for three consecutive months.

Brown and Matysiak (2000) argue that with high frequency data, sub-optimal approaches to valuation are likely to account for high kurtosis as true changes in the market may only be moderately integrated into the return series. Over longer holding periods it can be expected this effect would be less pronounced. Thus, as the reporting period between valuation dates increases the likelihood that property returns will be pulled from a normal distribution also increases. The rationale for behind is that as new information arrives randomly and continuously to surveyors the accumulative effect is likely to have greater impact as the interval between valuations increases. Brown and Matysiak (2000) also suggest that correlations might increase going from monthly to quarterly data but this result may be linked to the period under investigation.

The analysis herewith does not incorporate transaction costs. However as Lee and Stevenson (2005) argue a sound analysis of the transaction cost issue would require the

\footnotetext{
${ }^{6}$ The sum of money spent on purchases of new properties, expenditure on development and other capital expenditure, or received through sales. Sales include whole or part sales and other capital receipts.

${ }^{7}$ The sum of rent receivable plus other revenue receipts net of property specific management costs, ground rents and other irrecoverable expenditure
} 
addition of a number of assumptions concerning investor behaviour. Specifically it would be essential to examine in detail then most appropriate holding period for real estate and to accurately assess sensible costs, which to a large degree would be guided by the issue of illiquidity. The illiquid nature of real estate implies that assumptions would have to be made relating the level of movement that would be allowed with each specific holding period. Additionally Nozeman (2010) highlights that from an investor's perceptive there is a much higher focus at reducing corporate tax implications than diminishing transaction costs. Fisher et al. (2003) also argue that variations in liquidity of the real estate market over time make the interpretation of real estate price series more difficult. This is because prices tend to adjust slowly to changes in real estate market conditions. In fact, the nature of real estate markets causes adjustments to occur in prices, volumes and time to transact when market conditions change, as well as in the mix of assets being traded. As such, they indicate that real estate indices need to be adjusted to reflect the differential ability to enter and exit the market at different points of the real estate cycle. The IPD total returns by taking into consideration capital value, expenditure and net income to a certain extent take some of these adjustments into account. Finally Devaney and Diaz (2011) assert that heterogeneity of real estate assets, infrequent and irregular trading, private nature of transactions and the lack of a central market in which transactions take place presents barriers for obtaining the information necessary to measure accurate transaction costs. These imperfections lead to market prices that can differ from what would be expected in a competitive market. In other words, transaction prices and costs for identical properties are likely to vary. Besides, the absence of traded prices in the real estate market means that risk and return are inferred from valuations that are estimated from limited information on market transactions which relies on surveyors' knowledge of location, type of tenant, covenant, age of the property, general condition, lease structure etc. 
Starting with undiversified portfolios in the Office, Retail and Industry segments (viz. Office, Retail, Industry portfolios), equally weighted, sectorally diversified portfolios are constructed by combining the Office and Retail and the Office, Retail and Industry segment portfolios to yield Off_Ret and Off_Ret_Ind portfolios, respectively. Within a given segment, regional diversification is reflected in portfolios that are concentrated in London and then gradually expanded to incorporate the South-East and both the South-East and the Rest of the UK on an equally weighted basis. The approach to forming portfolios are based on previous studies such as Eichholtz et al. (1995) and Lee and Stevenson (2005a) who argue that this property type and super regional classification provides a viable portfolio investment strategy for investors in the UK. Additionally, limiting the number of sector-regions is also helpful to minimise optimisation errors with semi-definite matrices.

Excess returns for all portfolios are calculated using the yield on 10 year real zerocoupon gilts as a proxy for the risk free rate and adjusted to account for negative values. These are subsequently expressed in logs. Since the SFA approach used in this paper forms a generalised Sharpe Ratio measure, the logged value of the standard deviations of returns are also used.

Several SFA models are estimated beginning with the baseline, homoscedastic Model 1 which examines the relationship between the excess returns, InEx_returns, and the standard deviation, InStDev. When significant with a positively signed coefficient, the economic intuition of greater risk being associated with higher returns is confirmed. A time trend variable (Trend) is also included to account for frontier shifts over the period analysed. A positive and significant finding for this variable would indicate upward shifts of the frontier over time. This is quite relevant information as it captures a dynamic aspect of the frontier that instead of being fixed changes throughout the period under scrutiny perhaps, for example, due to changes in economic conditions and or investor behaviour. 
To accommodate periods of market peaks and troughs, dummy variables, Peaks and Troughs are used. A positive and significant Peak variable signifies greater returns during periods of market peaks via upward frontier shifts while a negative and significant Trough dummy variable indicates lower returns during market troughs through a downward shift in the frontier. The inclusion of the Peaks and Troughs dummy variable to Model 1 thus yields the homoscedastic Model 2.

To specifically assess the efficacy of diversification strategies in generating excess returns and placing portfolios on the benchmark frontier, dummy variables are used. Thus, the benefits to sectoral diversification are determined by evaluating returns of undiversified portfolios in Office, Retail or Industry sectors, each, against the returns of portfolios that incorporate the Office and Retail sectors (Off_Ret) and the Office, Retail and Industrial (Off_Ret_Ind) sectors. Similarly, to assess the benefits of regional diversification, an undiversified portfolio initially centred in the Office segment in London (Off_Lndn) is expanded into the South-East (Off_Lndn_SE) and finally into the rest of the UK, Off_Lndn_SE_Rest). In the same manner, regionally diversified portfolios are constructed within the Retail (Ret_Lndn, Ret_Lndn_SE, Ret_Lndn_Rest) and the Industrial (Ind_Lndn, Ind_Lndn_SE, Ind_Lndn_SE_Rest) segments. In doing so, the gains from regional diversification can be determined for a given segment. Model 3 (homoscedastic) places these diversification related variables on the frontier.

Model 4 extends Model 3 by assuming that the two-sided error component is heteroscedastic. Thus, the variance of the random error component is assumed to be a function of GDP ( $\ln G D P)$. Model 5 assumes that heteroscedasticity is limited to the inefficiency term so that its variance is a function of the diversification strategy adopted and GDP growth (GDP_growth). Whist controlling for heteroscedasticity, these variables are also 
represent the demand for commercial property space ${ }^{8}$. In Model 6, both error components are assumed to be heteroscedastic and modelled in the same manner as Models 4 and 5 .

Table 2 provides the descriptive statistics of monthly returns for the diversified and undiversified portfolios analysed over the period 1987-2016.

\section{[Insert Table 2]}

For the time period under investigation a portfolio of retail properties diversified in London yields the highest average return and risk whereas the same portfolio diversified between London the South-East produces the lowest mean return and standard deviations. Also whenever the office sector is used in sectoral or regional diversification the mean returns are smaller than for retail and the industrial sectors.

To verify the robustness of the results, all estimations are additionally carried out assuming an alternative exponential distribution for the technical inefficiency component of the SFA procedure. Models 7-12 present the results of the same.

\section{Results}

\subsection{Parameter Results}

Table 3 presents the results of the skewness, M3T and LR test for the presence of inefficiency. All three tests results, across all the estimated models confirm the appropriateness of using the SFA method at $1 \%$ significance level.

\section{[Insert Table 3]}

Models 1-5 display heteroscedasticity as evidenced by the LR test against the general Model 6. Thus, Model 6, which controls for heteroscedasticity in both error components is thus the preferred model and our analyses focus on the same.

\section{[Insert Table 4]}

\footnotetext{
${ }^{8}$ In addition to GDP and GDP growth rate, additionally, estimations were carried out using inflation (often hedged against using real estate) as a variance determinant. The estimations failed to converge.
} 
Turning to the parameter results, as can be seen from Model 6 in Table 4, the excess returns (lnEx_Ret) are significantly and positively related to risk (InStdev) confirming the economic intuition regarding the trade-off between risk and returns. The time trend variable (Trend) also indicates that the frontier has shifted upwards over the time frame under analysis. Additionally, market troughs are associated with lowered excess returns as evidenced by the negatively significant Trough variable with all results again significant at the $1 \%$ level. Similarly, market peaks are associated with higher excess returns as evidenced by the Peak variable. These results are found across Models 1-6.

Turning to the impact of diversification on portfolio returns, Model 6 indicates that in the retail segment, superior risk adjusted gains are obtained by portfolios centralised in London (Retail-London) while portfolios in the south-east and the rest of the UK (Retail-Se and Retail-RestUK) generate lower returns. This result may be a reflection of the London retail sector historically facing competition for space within main retail thoroughfares, due to international lifestyle, fashion brands, new concept stores, and restaurants. Byrne and Lee (2009) argue that the retail sector correlates with the urban hierarchy to focus on urban areas with large and dense populations with a greater stock of property. Undiversified portfolios in the retail sector overall (Sector -Retail) offer significantly lower gains than a portfolio concentrated solely in the Office-City segment. The Office segment in the Rest of the UK (Office-RestUK) is also found to provide lower returns as does the Office-Se-London-RestUk portfolio. Regional diversification within the office sector is thus, not found to yield significant returns. Sectoral diversifications are found to offer lower risk adjusted returns than undiversified an Office-City portfolio (Sector-Retail-London and Sector-Retail-LondonRestUK).

Turning to the determinants of inefficiency variance, interestingly, with the exception of portfolios concentrated in the Retail sector in London (Retail-London), both sectorally and 
spatially diversified portfolios lower the variance of inefficiency. Higher GDP growth is also associated with lower inefficiency variance.

As a robustness check, all the aforementioned SFA models are estimated under normal-exponential distributional assumptions. The results are presented in Table 4, Models 7-12 and the conclusions thereof are unchanged.

While the results thus far establish the significance of a given portfolio strategy in generating excess returns, the magnitude of deviation, from the frontier remains to be determined. Portfolio specific efficiencies are therefore presented and discussed in the following section.

\subsection{Portfolio Specific Efficiency Scores}

Table 5 presents the per annum average efficiency scores for the portfolios under analysis. These portfolio specific efficiencies are based on Model 6, Table 4. The average portfolio specific efficiencies range between $85 \%$ - 91\% over the full sample. This indicates that, broadly, there remains scope to increase returns by a further 9\%-15\%.

\section{[Insert Table 5]}

Looking at the temporal variation in the portfolio efficiencies, a general trend of increasing efficiency is observed across the time period under analysis. To gain a stronger sense of the dynamics of efficiency variation over the time period of the analysis, Table 6 presents the portfolio specific efficiencies averaged over a three year period at the beginning and at the end of the time period under study (Coelli et al., 1999), i.e. for 2014-2016 and 1987-1989. A ratio of the efficiencies under these two time periods is used to assess the dynamics of efficiency changes. When greater than unity, it signifies an improvement in efficiency towards the end of the time period under analysis, while a value lower than unity signifies a regression in efficiency towards the latter periods of the analysis.

\section{[Insert Table 6]}


The portfolios that evidenced an improvement in efficiency over the time period were Office_City and office_SE_London. These portfolios are, respectively, regionally concentrated in London and the South-East within the Office sector. Lee and Stevenson (2005) argue depending on investors 'ability to efficiently diversify a commercial property portfolio concentrated in a region will benefit from being diversified across regions within a property type or stay in the region and diversify across sectors.'

Overall, however, most of the portfolios evidence a slight decline in their efficiencies over the period, those within the Retail sector, both concentrated and regionally diversified, experiencing a relatively greater erosion of portfolio efficiency. This, however, belies per annum variations in efficiencies. Indeed, the per annum average portfolio efficiencies evidences a cross-board decline in 1990, 1992 and 2008 (Table 5). These can be associated with periods of economic downturns ${ }^{9}$. The tendency towards cyclical behaviour is more clearly evident in Table 7 which presents the 6-year averages of portfolio efficiency ${ }^{10}$. The cross-portfolio declines in efficiency clearly correspond to recessionary downturns.

\section{[Insert Table 7]}

\subsection{Discussion}

We begin by recognising that the portfolios, which through their construction, reflect particular diversification strategies, influence the benchmark frontier. They are, therefore, included as regressors in the estimation of the benchmark frontier thus allowing them to influence the shape and position of the frontier. The parameter results confirm the relevance of these portfolios towards and the presence of statistically significant gains from the same, be it spatial or sectoral. Additionally, the diversification variables are also assumed to

\footnotetext{
${ }^{9}$ The UK commercial property crashed in early 1990s. Between 1989 and 1993, UK commercial property prices fell by $27 \%$.

${ }^{10}$ See Grover and Grover (2013) for a comprehensive discussion about property cycles.
} 
influence the degree of inefficiency, specifically, the variance of inefficiency and are modelled as such following Hadri et al (2003).

Parsing the results under the two diversification strategies in more detail, as frontier position variables, the lack of and/or negatively significant spatial returns in the Office sector is of interest. This is particularly so in light of the findings by Byrne and Lee (2006, 2009, 2010) who report evidence of spatial concentration within this sector. An interesting perspective is offered by Henneberry and Roberts (2008) that may help explain this result. The authors indicate that the presence of a comprehensive and readily available information set relating to an investment region compels investors to focus on that region, regardless of investment fundamentals. By the same token, paucity of information relating to regions detracts from investment in those regions. Crucially therefore, investors may adopt various heuristics to complement their investment analysis. In the context of our results therefore, this herding mentality coupled with heuristic biases may explain the absence of/negatively significant gains from spatial diversification within the Office segment. Byrne et al. (2013) argue that benchmarking provides a reference point for the assessment of investment performance, and the UK investors' spatially concentrated behaviour may result in benchmarks that are not based on economic rationale looking for utility maximisation but based on facts other than views and beliefs of the peers.

Of interest, however, is the degree to which diversification leads to lower variations in inefficiency. Here, with the exception of undiversified portfolios in the retail sector within London, all portfolios yield a reduction in inefficiency variance. Specifically, portfolios within the retail sector in the South-east and rest of UK, the industrial sector in London and regionally diversified portfolios within the Industry segment appear to offer the greatest reduction in the variability of inefficiency. Thus, while the returns are lower relative to the 
Office_City portfolio, diversification helps to alleviate variability in the magnitude of inefficiency.

Turning to the portfolio specific efficiencies, the first thing to note is that a manager's ability to manoeuvre portfolios onto the benchmark frontier is an outcome of a combination of economic analyses, innate skill and random luck. The latter is not analysed herein as over the extended time period under analysis, the impact of good and bad luck is averaged out. Economic analyses and innate ability, however, are interlinked. Optimising portfolio returns requires sound analysis of market fundamentals and macroeconomic conditions. Evaluating the outcome of these analyses and interpreting the same reflects the judgement and experience of the manager. Thus, the realised portfolio efficiencies and relatedly, the inefficiency of the same, reflect the experience and skill of the manager in constructing, diversifying and managing optimal portfolios. However, the realised portfolio (in) efficiencies are not a pure indication of such ability. This is because factors such as the costs associated with portfolio adjustments, for example, can constrain the ability of a portfolio manager to attain benchmark portfolio efficiency. For example, illiquidity of direct real estate portfolios makes it costly to be re-balanced.

The scaling property contained within the SFA models used in this paper, affords the following economic interpretation for the realised portfolio (in)efficiency scores. $u_{i t}$ is the baseline inefficiency level of the portfolio reflecting innate management skills while the degree to which such skills are successfully deployed to attain efficient performance depends on the diversification strategies adopted (a reflection of the portfolio manager's judgement and experience) and the wider macroeconomic environment. Together, these factors yield a realised efficiency score of 85\%-91. The portfolio specific efficiencies clearly point to substantial unrealised gains across all portfolios, i.e. all diversification strategies.

\section{Conclusion}


This study examined the efficiencies of UK real estate portfolios over 1987-2016.

Taking into account the shortcoming of Modern Portfolio Theory to determine direct property efficiency portfolios a benchmark efficiency frontier was econometrically determined using Stochastic Frontier Analysis which (i) enabled an assessment of the capacity of various diversification strategies to generate significant excess returns and (ii) identify portfolio specific efficiencies indicative of the magnitude of deviation, if any, of a given portfolio from the benchmark frontier and (iii) identified the benchmark efficiency frontier econometrically. The findings confirm the efficacy of regional and sectoral diversification in reducing the variance of inefficiency. These findings were robust to heteroscedasticity and alternative specifications of the empirical frontier model. The realised portfolio specific efficiencies, averaging at 85\% - 91\% indicated scope to further improve performance.

Worth noting within the study are the following points. In addition to risk, portfolio returns are also influenced by environmental factors such as the costs of portfolio management and supply side variables such as construction levels. Due to unavailability of data for the time span considered, we were unable to include these variables in the estimation procedure. The availability and inclusion of such variables offers an avenue to extend the research presented herein. An examination of this issue is left for future work. Another point worthy of future investigation is related to the benchmark efficiency frontier proxies usually considered by investors performance analysis and a comparison of those with the econometrically defined frontiers generated by SFA.

Finally, to the authors' knowledge, this is the first study to examine real estate portfolio diversification gains using Stochastic Frontier Analysis. It is hoped that further studies along the aforementioned lines will generalise the findings using this econometric approach. 


\section{References}

Almond, N. (2015) “Risks from overheating markets”, Money into Property 2015, DTZ Research.

Almond, N. (2017) “ Great Wall of Money”, Cushman \& Wakefield Research.

Andrew, M., Devaney, S. and Lee, S. (2003), Another Look at the Relative Importance of Sectors and Regions in Determining Property Returns, Working Papers in Real Estate and Planning 14/03, Department of Real Estate and Planning, University of Reading, Reading.

Annaert, J., van den Broeck, J. and Vander Vennet, R. (2003) Determinants of mutual fund performance: a Bayesian stochastic frontier approach, European Journal of Operational Research, 151, 617-632.

Aigner, D., Knox Lovell, C. A. and Schmidt, P. (1977) Formulation and estimation of stochastic frontier production function models, Journal of Econometrics, 6, 21-37.

Alvarez, A., Amsler, C., Orea, L. and Schmidt, P. (2006). Interpreting and testing the scaling property in models where inefficiency depends on firm characteristics, Journal of Productivity Analysis, 25 (3), pp. 201-212.

Battese, G.E. and Coelli, T.G. (1988). Prediction of firm-level technical efficiencies with a generalised frontier production function and panel data, Journal of Econometrics, vol. 38, pp.387-399.

Battese, G.E. and Coelli, T.J. (1995). A model for technical inefficiency effects in a stochastic frontier production function for panel data, Empirical Economics, Vol. 20, pp.325-32.

Brandt, M., Santa-Clara P., Valkanov, R. (2009) "Parametric portfolio policies: Exploiting characteristics in the cross section of equity returns”, Review of Financial Studies, 22, pp.3411-3447.

Brown, G. R and Matysiak, G. A. (2000) Real Estate Investment: A Capital Market Approach, Financial Times Prentice Hall, ISBN-10: 0130200638, ISBN-13: 9780130200631.

Byrne, P. and Lee, S. (2000), "Risk reduction in the United Kingdom property market”, Journal of Property Research, Vol. 17 No. 1, pp. 23-46. 
Byrne, P., \& Lee, S. (2006). Geographical concentration in the institutional market for office property in England and Wales. Working Papers in Real Estate \& Planning 07/06, Department of Real Estate \& Planning, University of Reading, Reading.

Byrne, P., \& Lee, S. (2009). Spatial concentration in institutional investment in the UK: Some comparisons between the retail and office sectors. Journal of Property Investment and Finance, 27, pp. 5-24.

Byrne, P., \& Lee, S. (2010). Spatial concentration in industrial real estate: Institutional investment in England and Wales. Journal of Property Investment and Finance, 28, pp. 6-23.

Byrne, P., \& Lee, S. (2011). Sector, region or function? A MAD reassessment of real estate diversification in Great Britain. Journal of Property Investment and Finance, 29, 167189.

Byrne, P., Jackson C., Lee S. (2013),"Bias or rationality? The case of UK commercial real estate investment", Journal of European Real Estate Research, Vol. 6 Iss 1 pp. 6 - 33

Chen, P. and Liang, Y. (2000), “Optimal diversification: is it really worthwhile?”, Journal of Real Estate Portfolio Management, Vol. 6, pp. 7-16.

Coelli, T.G. (1995). Estimators and hypothesis tests for a stochastic frontier function: A monte carlo analysis, Journal of Productivity Analysis, Vol. 6 (4), pp. 647-268.

Coelli, T., Perelman, S., Romano, E. (1999). Accounting for environmental influences in stochastic frontier models: With application to international airlines, Journal of Productivity Analysis, Vol. 1, pp. 251-273.

Coleman S. and Leone V. (2015), “An investigation of regime shifts in UK commercial property returns: a time series analysis”, Applied Economics, 47:60, 6479-6492

Cullen, I. (1993), “Cluster analysis and property risk”, The Cutting Edge - Proceedings of the RICS Property Research Conference, RICS, London, pp. 21-36.

Devaney, S. and Martinez Diaz, R. (2011), Transaction based indices for the UK commercial real estate market: an exploration using IPD transaction data, Journal of Property Research, Vol. 28 No. 4, pp. 269-289.

Eichholz, P.M.A., Hoesli, M., MacGregor, B.D. and Nanthakumaran, N. (1995), "Real estate diversification by property type and region”, Journal of Property Finance, Vol. 6 No. 3, pp. 39-59

Fisher, J.D. and Liang, Y. (2000), "Is property-type diversification more important than regional diversification?”, Real Estate Finance, Vol. 17 No. 3, pp. 35-40. 
Fisher, J., Gatzlaff, D., Geltner, D. and Haurin, D. (2003), Controlling for the Impact of Variable Liquidity in Commercial Real Estate Price Indices. Real Estate Economics, 31 (2), 269-303.

Gibbons, M., Ross, S. and Shanken, J. (1989), “A test of the efficiency of a given portfolio”, Econometrica, Vol. 57, pp. 1121-52.

Grover R., and Grover C. (2013) Property Cycles, Journal of Property Investment \& Finance Vol. 31 No. 5, pp. 502-516.

Hadri, K. (1999). Estimation of a doubly heteroscedastic frontier cost function. Journal of Business \& Economic Statistics, 17(3), 359-363.

Hadri, K., Guermat, C., \& Whittaker, J. (2003). Estimation of technical inefficiency effects using panel data and doubly heteroscedastic stochastic production frontiers. Empirical Economics, 28, 203-222.

Hamelink, F., Hoesli, M., Lizieri, C. and MacGregor, B.D. (2000), “Homogeneous commercial property market groupings and portfolio construction in the United Kingdom”, Environment and Planning A, Vol. 32 No. 2, pp. 323-44.

Henneberry, J., Mouzakis, F. and Rowley, R. (2004), "Region-building: funding the development of business property in the regions”, paper presented at seminar of the Regional Studies Association Working Group on Financing Regional Economies, Newcastle, December.

Hennebury, J. and Roberts, C. (2008) Calculated Inequality? Portfolio Benchmarking and Regional Office Property Investment in the UK. Urban Studies, 45, 5\&6, 1217-1241.

Hoesli, M., Lizieri, C. and MacGregor, B. (1997), “The spatial dimensions of the investment performance of UK commercial property”, Urban Studies, Vol. 34 No. 9, pp. 1475-94.

Hoesli, M. and MacGregor, B. (2000) Property Investment: principles and practice of portfolio management, Longman, Harrow.

Heston, S.L. and Rouwenhorst, K.G. (1994). Does industrial structure explain the benefits of international diversification?, Journal of Financial Economics, Vol.36, pp.3-27.

Hu, J.H., Chang, T., Yeutien, R. (2013). Market condition and the effect of diversification on mutual fund performance: should finds be more concentrative under crisis? Journal of Productivity Analysis, February 2014, Vol. 41, No. 1, pp 141-151.

Jackson, C. (2002). Classifying local retail property markets on the basis of retail rental growth rates. Urban Studies, 39, 1417-1438. 
Jackson, C., \& White, M. (2005a). Inflation and multi-level influences on industrial property rents. Journal of Property Investment and Finance, 23, 342-363.

Jackson, C., \& White, M. (2005b). Challenging traditional real estate market classifications for investment diversification. Journal of Real Estate Portfolio Management, 11, 307-321.

Jackson C. (2013), “Diversification of portfolio risk: reconciling theory and observed Weightings”, Journal of Property Research, Vol. 30, No. 4, pp. 266-297.

Jobson, J.D. and Korkie, B. (1981), "Performance hypothesis testing with the sharpe and treynor measures”, Journal of Finance, Vol. 36, pp. 888-908.

Kodde, D.A. and Palme, F.C. (1986). Wald criteria for jointly testing equality and inequality restrictions, Econometrica, Vol.54, pp.1243-1248.

Kumbhakar, S.C. and Lovell, C.A.K. (2000). Stochastic Frontier Analysis, Cambridge University Press, ISBN: 0521666635.

Lee, S. and Byrne, P. (1998), "Diversification by sector, region or function? A mean absolute deviation optimisation”, Journal of Property Valuation and Investment, Vol. 16 No. 1,pp. 38-56.

Lee, S., and Stevenson S. (2005), “Testing the statistical significance of sector and regional diversification”, Journal of Property Investment and Finance, 23, 5, pp.39-411.

Lee, S. and Devaney, S. (2007) The Changing Importance of Sector and Regional Factors in Real Estate Returns: 1987-2002, Journal of Property Research, 24:1, 55-69.

Lizieri, C.M. and Ward, C.W.R. (2001), “The distribution of commercial real estate returns”, in Knight, J. and Satchell, S. (Eds), Return Distributions in Finance, ButterworthHeinemann, Oxford, Ch. 3.

Markowitz, H. (1952), “Portfolio selection”, The Journal of Finance, Vol. 7 No. 1, pp. 77-91.

McGreal, Stanley;Adair, Alastair;Berry, James N;Webb, James R (2006). Institutional real estate portfolio diversification in Ireland and the UK, Journal of Property Investment \& Finance, Vol. 24, No.2.

Meeusen, W. and van den Broeck, J. (1977) Efficiency estimation from Cobb-Douglas production functions with composed error, International Economic Review, 18, 435-444.

Newell, G. and Yen Keng, T. (2003). The significance of property sector and geographic diversification in Australian property portfolios, Pacific Rim Property Research Journal, Vol. 9 (3).

Nozeman, E. (2010). Transaction costs in commercial real estate: an European comparison, $17^{\text {th }}$ Annual European real Estate Society Conference, pp.1-11. 
Plazzi, A.,Torous, W., Valkanov, R. (2011), “Exploiting property characteristics in commercial real estate portfolio allocation”, Journal of Portfolio Management; 2011; 37, 5; pp. 3949.

Santos, A., Tusi, J., Da Costa Jr, J. and Da Silva, S (2005) Evaluating Brazilian mutual funds with stochastic frontiers, Economic Bulletin, 13 (2), 1-6.

Sharpe, W.F. (1966) A simplified model for portfolio analysis, Management Science 9 (2), 277-93.

Young, M.S. and Graff, R.A. (1995), "Real estate is not normal: a fresh look at real estate return distributions”, Journal of Real Estate Finance and Economics, Vol. 10 No. 3, pp. 225-59.

Young, M.S., Lee, S.L. and Devaney, S.P. (2006), “Non-normal real estate return distributions by property type in the UK”, Journal of Property Research, Vol. 23 No. 2, pp. 109-33.

Young, M.S. (2008), “Revisiting non-normal real estate return distributions by property type in the US”, Journal of Real Estate Finance and Economics, Vol. 36 No. 2, pp. 233-48. 
Table 1: IPD UK Monthly Property database

\begin{tabular}{lcccc}
\hline & Capital value $(\mathrm{Em})$ & Av. Property Value $(\mathrm{Em})$ & Number of properties & $\begin{array}{c}\text { Number of } \\
\text { portfolios }\end{array}$ \\
\hline All property & 46,965 & 14.1 & 3,341 & 48 \\
Retail & 17,500 & 12.6 & 1,385 & 44 \\
Office & 16,440 & 21.1 & 779 & 47 \\
Industrial & 9,685 & 10.7 & 902 & 45 \\
Residential & 379 & 17.2 & 22 & 9 \\
Hotel & 871 & 10.8 & 81 & 23 \\
Other & 2,089 & 12.1 & 172 & 33 \\
\hline
\end{tabular}


Table 2: Descriptive statistics of average returns

\begin{tabular}{lcccccc}
\hline Portfolio & Mean & Min & Max & Skewness & Kurtosis & Std. Dev. \\
\hline Office-City & 0.60 & -7.58 & 5.24 & -1.50 & 8.78 & 1.57 \\
Retail-SE & 0.71 & -5.38 & 3.72 & -1.39 & 10.71 & 0.96 \\
Retail-London & 1.67 & -10.85 & 11.13 & -1.08 & 10.45 & 2.07 \\
Retail-RestUK & 0.60 & -4.49 & 4.75 & -1.23 & 9.80 & 0.95 \\
Office-SE & 0.68 & -4.50 & 4.65 & -0.93 & 6.81 & 1.12 \\
Office-RestUK & 0.73 & -4.50 & 4.70 & -0.65 & 7.76 & 1.15 \\
Ind-SE & 0.89 & -5.00 & 4.92 & -1.01 & 7.86 & 1.09 \\
Ind-London & 0.96 & -5.47 & 8.01 & -0.41 & 11.24 & 1.17 \\
Ind-RestUK & 0.94 & -4.78 & 5.67 & -0.56 & 9.12 & 1.11 \\
Sector-Retail & 0.68 & -5.78 & 4.23 & -1.76 & 11.48 & 1.09 \\
Sector-Office & 0.73 & -5.31 & 3.81 & -1.36 & 7.83 & 1.19 \\
Sector-Ind. & 0.89 & -4.85 & 4.82 & -1.00 & 8.32 & 1.07 \\
Ret.SE-Ret.London & 1.09 & -2.32 & 7.38 & 0.96 & 4.77 & 1.59 \\
Ret.SE-London-RestUK & 0.96 & -1.82 & 5.69 & 0.92 & 4.39 & 1.31 \\
Office-SE-London & 0.45 & -3.92 & 3.71 & -0.26 & 3.52 & 1.33 \\
Office-SE-London-RestUK & 0.63 & -2.32 & 3.34 & 0.08 & 2.56 & 1.21 \\
Ind.-SE-London & 0.98 & -0.99 & 6.47 & 1.12 & 5.48 & 1.20 \\
Ind.-SE-London-RestUK & 1.09 & -0.88 & 5.89 & 1.03 & 4.33 & 1.17 \\
Sector-Retail-London & 0.71 & -1.87 & 3.70 & 0.49 & 3.01 & 1.01 \\
Sector-retail-London-restUK & 0.83 & -1.61 & 3.44 & 0.55 & 2.68 & 1.03 \\
\hline
\end{tabular}


Table 3: Tests for SFA

\begin{tabular}{|c|c|c|c|c|}
\hline SFA Model / Test & Skew test & M3T test & LR Test & Log likelihood \\
\hline (1) & $-2.462 * * *$ & $-12.713^{* * *}$ & $493.570 * * *$ & $1294.551 * * *$ \\
\hline (2) & $-2.482 * * *$ & $-12.818^{* * *}$ & $573.989 * * *$ & $1309.124^{* * *}$ \\
\hline (3) & $-2.588 * * *$ & $-13.369 * * *$ & $618.377^{* * *}$ & $1356.954 * * *$ \\
\hline (4) & & & $1568.706 * * *$ & $1520.033^{* * *}$ \\
\hline (5) & & & $1568.706 * * *$ & $1832.119 * * *$ \\
\hline (6) & & & $2155.142^{* * *}$ & $2125.337^{* * *}$ \\
\hline (7) & & & $941.220 * * *$ & $1477.069 * * *$ \\
\hline (8) & & & $961.042 * * *$ & $1502.650 * * *$ \\
\hline (9) & & & $1001.917^{* * *}$ & $1548.725^{* * *}$ \\
\hline (10) & & & $1728.651^{* * *}$ & $1912.092 * * *$ \\
\hline (11) & & & $1651.279 * * *$ & $1873.405^{* * *}$ \\
\hline$(12)$ & & & $2508.432 * * *$ & $2301.982 * * *$ \\
\hline Observations & 2,340 & 2,340 & 2,340 & 2,340 \\
\hline
\end{tabular}


Table 4: SFA Parameter results

\begin{tabular}{|c|c|c|c|c|c|c|c|c|c|c|c|c|}
\hline \multirow[t]{2}{*}{ Inexret } & \multirow[t]{2}{*}{$(1)$} & $(2)$ & (3) & (4) & (5) & (6) & (7) & (8) & (9) & $(10)$ & $(11)$ & $(12)$ \\
\hline & & \multicolumn{5}{|c|}{ Normal/half-normal distribution } & \multicolumn{6}{|c|}{ Normal/exponential distribution } \\
\hline Instdev & $\begin{array}{c}0.037 * * * \\
(0.002)\end{array}$ & $\begin{array}{c}0.038^{* * *} \\
(0.002)\end{array}$ & $\begin{array}{c}0.035^{* * *} \\
(0.002)\end{array}$ & $\begin{array}{c}0.016 * * * \\
(0.002)\end{array}$ & $\begin{array}{c}0.033^{* * *} \\
(0.002)\end{array}$ & $\begin{array}{c}0.018^{* * *} \\
(0.002)\end{array}$ & $\begin{array}{c}0.044^{* * *} \\
(0.002)\end{array}$ & $\begin{array}{c}0.045^{* * *} \\
(0.002)\end{array}$ & $\begin{array}{c}0.042 * * * \\
(0.002)\end{array}$ & $\begin{array}{c}0.021 * * * \\
(0.001)\end{array}$ & $\begin{array}{c}0.040 * * * \\
(0.002)\end{array}$ & $\begin{array}{c}0.022 * * * \\
(0.001)\end{array}$ \\
\hline Trend & $\begin{array}{c}0.013 * * * \\
-0.000\end{array}$ & $\begin{array}{c}0.013^{* * *} \\
(0.000)\end{array}$ & $\begin{array}{c}0.012 * * * \\
(0.000)\end{array}$ & $\begin{array}{c}0.016^{* * *} \\
(0.000)\end{array}$ & $\begin{array}{c}0.014 * * * \\
(0.000)\end{array}$ & $\begin{array}{c}0.018 * * * \\
(0.000)\end{array}$ & $\begin{array}{c}0.014 * * * \\
(0.0002)\end{array}$ & $\begin{array}{c}0.014 * * * \\
(0.0002)\end{array}$ & $\begin{array}{c}0.014 * * * \\
(0.0002)\end{array}$ & $\begin{array}{c}0.018 * * * \\
(0.0002)\end{array}$ & $\begin{array}{c}0.015^{* * *} \\
(0.0002)\end{array}$ & $\begin{array}{l}0.019 * * * \\
(0.00020\end{array}$ \\
\hline Peak & & $\begin{array}{c}0.032 * * * \\
(0.011)\end{array}$ & $\begin{array}{c}0.027^{* *} \\
(0.011)\end{array}$ & $\begin{array}{l}0.021 * * \\
(0.0110)\end{array}$ & $\begin{array}{c}0.028^{* * *} \\
(0.009)\end{array}$ & $\begin{array}{c}0.017 * * \\
(0.007)\end{array}$ & & $\begin{array}{c}0.029 * * * \\
(0.009)\end{array}$ & $\begin{array}{c}0.025^{* * *} \\
(0.008)\end{array}$ & $\begin{array}{c}0.013^{* *} \\
(0.006)\end{array}$ & $\begin{array}{c}0.025^{* * *} \\
(0.008)\end{array}$ & $\begin{array}{c}0.012 * * \\
(0.005)\end{array}$ \\
\hline trough & & $\begin{array}{c}-0.060 * * * \\
(0.012)\end{array}$ & $\begin{array}{c}-0.056^{* * *} \\
(0.012)\end{array}$ & $\begin{array}{c}-0.044^{* * *} \\
(0.007)\end{array}$ & $\begin{array}{c}-0.058^{* * *} \\
(0.010)\end{array}$ & $\begin{array}{c}-0.037 * * * \\
(0.006)\end{array}$ & & $\begin{array}{c}-0.07 * * * \\
(0.010)\end{array}$ & $\begin{array}{c}-0.07^{* * *} \\
(0.010)\end{array}$ & $\begin{array}{c}-0.04 * * * \\
(0.005)\end{array}$ & $\begin{array}{c}-0.063 * * * \\
(0.009)\end{array}$ & $\begin{array}{c}-0.036 * * * \\
(0.005)\end{array}$ \\
\hline Retail-SE & & & $\begin{array}{c}0.007 \\
(0.014)\end{array}$ & $\begin{array}{l}-0.007 \\
(0.012)\end{array}$ & $\begin{array}{c}-0.034^{* *} \\
(0.017)\end{array}$ & $\begin{array}{c}-0.030 * * \\
(0.011)\end{array}$ & & & $\begin{array}{c}0.004 \\
(0.013)\end{array}$ & $\begin{array}{l}-0.009 \\
(0.008)\end{array}$ & $\begin{array}{l}-0.022 \\
(0.015)\end{array}$ & $\begin{array}{c}-0.022^{* *} \\
(0.009)\end{array}$ \\
\hline Retail-London & & & $\begin{array}{c}0.103 * * * \\
(0.014)\end{array}$ & $\begin{array}{c}0.096 * * * \\
(0.011)\end{array}$ & $\begin{array}{c}0.105^{* * *} \\
(0.019)\end{array}$ & $\begin{array}{c}0.106 * * * \\
(0.014)\end{array}$ & & & $\begin{array}{c}0.092 * * * \\
(0.013)\end{array}$ & $\begin{array}{c}0.091^{* * *} \\
(0.009)\end{array}$ & $\begin{array}{c}0.094 * * * \\
(0.017)\end{array}$ & $\begin{array}{c}0.096 * * * \\
(0.011)\end{array}$ \\
\hline Retail-RestUK & & & $\begin{array}{c}0.002 \\
(0.014)\end{array}$ & $\begin{array}{l}-0.014 \\
(0.012)\end{array}$ & $\begin{array}{c}-0.042 * * \\
(0.017)\end{array}$ & $\begin{array}{c}-0.037^{* * *} \\
(0.012)\end{array}$ & & & $\begin{array}{c}0.001 \\
(0.013)\end{array}$ & $\begin{array}{c}-0.017^{*} \\
(0.009)\end{array}$ & $\begin{array}{c}-0.027 * \\
(0.015)\end{array}$ & $\begin{array}{c}-0.032 * * * \\
(0.010)\end{array}$ \\
\hline Office-SE & & & $\begin{array}{c}0.019 \\
(0.014)\end{array}$ & $\begin{array}{c}0.001 \\
(0.011)\end{array}$ & $\begin{array}{l}-0.012 \\
(0.018)\end{array}$ & $\begin{array}{l}-0.014 \\
(0.011)\end{array}$ & & & $\begin{array}{c}0.013 \\
(0.013)\end{array}$ & $\begin{array}{c}0.0002 \\
(0.0085)\end{array}$ & $\begin{array}{l}-0.005 \\
(0.016)\end{array}$ & $\begin{array}{l}-0.008 \\
(0.009)\end{array}$ \\
\hline Office-RestUK & & & $\begin{array}{l}0.025^{*} \\
(0.014)\end{array}$ & $\begin{array}{l}-0.011 \\
(0.012)\end{array}$ & $\begin{array}{l}-0.012 \\
(0.018)\end{array}$ & $\begin{array}{c}-0.027^{* *} \\
(0.01)\end{array}$ & & & $\begin{array}{c}0.015 \\
(0.013)\end{array}$ & $\begin{array}{l}-0.010 \\
(0.079)\end{array}$ & $\begin{array}{l}-0.003 \\
(0.013)\end{array}$ & $\begin{array}{c}-0.025^{* *} \\
(0.069)\end{array}$ \\
\hline Ind-SE & & & $\begin{array}{c}0.035^{* *} \\
(0.014)\end{array}$ & $\begin{array}{c}0.009 \\
(0.011)\end{array}$ & $\begin{array}{r}-0.0002 \\
(0.018)\end{array}$ & $\begin{array}{l}-0.012 \\
(0.011)\end{array}$ & & & $\begin{array}{c}0.028 * * \\
(0.013)\end{array}$ & $\begin{array}{c}0.006 \\
(0.008)\end{array}$ & $\begin{array}{c}0.008 \\
(0.016)\end{array}$ & $\begin{array}{l}-0.005 \\
(0.009)\end{array}$ \\
\hline Ind-London & & & $\begin{array}{c}0.028 * * \\
(0.014)\end{array}$ & $\begin{array}{c}0.015 \\
(0.012)\end{array}$ & $\begin{array}{l}-0.009 \\
(0.017)\end{array}$ & $\begin{array}{l}-0.010 \\
(0.011)\end{array}$ & & & $\begin{array}{l}0.022^{*} \\
(0.013)\end{array}$ & $\begin{array}{c}0.009 \\
(0.008)\end{array}$ & $\begin{array}{c}0.001 \\
(0.016)\end{array}$ & $\begin{array}{l}-0.004 \\
(0.009)\end{array}$ \\
\hline Ind-RestUK & & & $\begin{array}{c}0.046 * * * \\
(0.015)\end{array}$ & $\begin{array}{l}0.0073 \\
(0.012)\end{array}$ & $\begin{array}{c}0.002 \\
(0.0185)\end{array}$ & $\begin{array}{l}-0.017 \\
(0.012)\end{array}$ & & & $\begin{array}{c}0.033 * * \\
(0.013)\end{array}$ & $\begin{array}{l}0.0004 \\
(0.008)\end{array}$ & $\begin{array}{c}0.008 \\
(0.016)\end{array}$ & $\begin{array}{l}-0.013 \\
(0.009)\end{array}$ \\
\hline Sector-Retail & & & 0.005 & $-2.96 e-05$ & $-0.032^{*}$ & $-0.022 *$ & & & 0.003 & -0.008 & -0.020 & $-0.022 * *$ \\
\hline
\end{tabular}




\begin{tabular}{|c|c|c|c|c|c|c|c|c|c|c|c|c|}
\hline \multirow[t]{2}{*}{ Inexret } & \multirow[t]{2}{*}{ (1) } & $(2)$ & (3) & (4) & (5) & \multirow[t]{2}{*}{ (6) } & (7) & (8) & (9) & $(10)$ & $(11)$ & $(12)$ \\
\hline & & \multicolumn{4}{|c|}{ Normal/half-normal distribution } & & \multicolumn{6}{|c|}{ Normal/exponential distribution } \\
\hline & & & $(0.014)$ & $(0.013)$ & $(0.017)$ & $(0.013)$ & & & $(0.013)$ & $(0.009)$ & $(0.015)$ & $(0.009)$ \\
\hline \multirow{2}{*}{\multicolumn{3}{|c|}{ Sector-Office }} & 0.021 & -0.0009 & -0.001 & -0.015 & & & 0.020 & -0.001 & 0.006 & -0.010 \\
\hline & & & $(0.014)$ & $(0.011)$ & $(0.018)$ & $(0.011)$ & & & $(0.013)$ & $(0.008)$ & $(0.016)$ & $(0.009)$ \\
\hline \multirow{2}{*}{\multicolumn{3}{|c|}{ Sector-Ind. }} & $0.043 * * *$ & 0.008 & 0.003 & -0.012 & & & $0.034 * *$ & 0.006 & 0.012 & -0.005 \\
\hline & & & $(0.014)$ & $(0.011)$ & $(0.018)$ & $(0.011)$ & & & $(0.013)$ & $(0.008)$ & $(0.016)$ & $(0.009)$ \\
\hline \multirow{2}{*}{\multicolumn{3}{|c|}{ Ret.SE+Ret.London }} & $0.036 * *$ & $0.035 * * *$ & 0.017 & $0.025^{*}$ & & & $0.027^{* *}$ & $0.028 * * *$ & 0.016 & $0.021 * *$ \\
\hline & & & $(0.014)$ & $(0.011)$ & $(0.018)$ & $(0.013)$ & & & $(0.013)$ & $(0.009)$ & $(0.016)$ & $(0.010)$ \\
\hline \multirow{2}{*}{\multicolumn{3}{|c|}{ Ret.SE+London+RestUK }} & $0.027^{*}$ & 0.019 & -0.0004 & 0.004 & & & $0.022 *$ & 0.014 & 0.004 & 0.003 \\
\hline & & & $(0.014)$ & $(0.012)$ & $(0.017)$ & $(0.012)$ & & & $(0.013)$ & $(0.009)$ & $(0.015)$ & $(0.010)$ \\
\hline \multirow{2}{*}{\multicolumn{3}{|c|}{ Office-SE-London }} & -0.001 & -0.004 & -0.015 & -0.014 & & & -0.002 & -0.005 & -0.010 & -0.010 \\
\hline & & & $(0.014)$ & $(0.010)$ & $(0.017)$ & $(0.019)$ & & & $(0.013)$ & $(0.008)$ & $(0.016)$ & $(0.009)$ \\
\hline \multirow{2}{*}{\multicolumn{3}{|c|}{ Office-SE-London-RestUK }} & 0.001 & -0.009 & -0.019 & $-0.022 *$ & & & -0.0009 & -0.010 & -0.014 & $-0.018 * *$ \\
\hline & & & $(0.014)$ & $(0.011)$ & $(0.017)$ & $(0.011)$ & & & $(0.013)$ & $(0.008)$ & $(0.016)$ & $(0.009)$ \\
\hline \multirow{2}{*}{\multicolumn{3}{|c|}{ Ind.-SE-London }} & $0.033^{* *}$ & 0.013 & -0.005 & -0.010 & & & $0.025^{* *}$ & 0.008 & 0.003 & -0.003 \\
\hline & & & $(0.014)$ & $(0.011)$ & $(0.018)$ & $(0.011)$ & & & $(0.013)$ & $(0.008)$ & $(0.016)$ & $(0.009)$ \\
\hline \multirow{2}{*}{\multicolumn{3}{|c|}{ Ind.-SE-London-RestUK }} & $0.030 * *$ & 0.007 & -0.010 & -0.016 & & & $0.022^{*}$ & 0.002 & -0.001 & -0.011 \\
\hline & & & $(0.014)$ & $(0.011)$ & $(0.018)$ & $(0.011)$ & & & $(0.013)$ & $(0.008)$ & $(0.016)$ & $(0.009)$ \\
\hline \multirow{2}{*}{\multicolumn{3}{|c|}{ Sector-Retail+London }} & 0.008 & -0.006 & -0.023 & $-0.025 * *$ & & & 0.006 & -0.010 & -0.013 & $-0.022 * *$ \\
\hline & & & $(0.014)$ & $(0.012)$ & (0.017) & $(0.012)$ & & & $(0.013)$ & $(0.008)$ & $(0.015)$ & $(0.009)$ \\
\hline \multirow{2}{*}{\multicolumn{3}{|c|}{ Sector-retail+London+restUK }} & 0.016 & -0.003 & -0.017 & $-0.023 * *$ & & & 0.013 & -0.006 & -0.007 & $-0.019 * *$ \\
\hline & & & $(0.014)$ & $(0.012)$ & $(0.017)$ & $(0.011)$ & & & $(0.013)$ & $(0.008)$ & $(0.015)$ & $(0.009)$ \\
\hline \multirow[t]{2}{*}{ Constant } & $2.375^{* * *}$ & $2.372 * * *$ & $2.352 * * *$ & $2.244 * * *$ & $2.318^{* * *}$ & $2.213^{* * *}$ & $2.328 * * *$ & $2.326 * * *$ & $2.308 * * *$ & $2.183^{* * *}$ & $2.284 * * *$ & $2.172 * * *$ \\
\hline & -0.007 & $(0.007)$ & $(0.0119$ & $(0.011)$ & $(0.014)$ & $(0.010)$ & $(0.006)$ & $(0.006)$ & $(0.010)$ & $(0.008)$ & $(0.012)$ & $(0.008)$ \\
\hline \multirow{2}{*}{\multicolumn{2}{|c|}{ Retail-SE }} & & & & $-1.182 * * *$ & $-1.126 * * *$ & & & & & $-1.211 * * *$ & $-1.240 * * *$ \\
\hline & & & & & $(0.290)$ & $(0.254)$ & & & & & $(0.391)$ & (0.371) \\
\hline
\end{tabular}




\begin{tabular}{|c|c|c|c|c|}
\hline \multirow[t]{2}{*}{ Inexret } & $(2)$ & (3) & (5) & (6) \\
\hline & \multicolumn{4}{|c|}{ Normal/half-normal distribution } \\
\hline \multirow[t]{2}{*}{ Retail-London } & & & 0.0352 & 0.0875 \\
\hline & & & $(0.243)$ & $(0.236)$ \\
\hline \multirow[t]{2}{*}{ Retail-RestUK } & & & $-1.223 * * *$ & $-1.029 * * *$ \\
\hline & & & $(0.295)$ & $(0.253)$ \\
\hline \multirow[t]{2}{*}{ Office-SE } & & & $-0.669 * *$ & $-0.687 * * *$ \\
\hline & & & $(0.265)$ & $(0.243)$ \\
\hline \multirow[t]{2}{*}{ Office-RestUK } & & & $-0.761^{* * *}$ & $-0.836 * * *$ \\
\hline & & & $(0.271)$ & $(0.242)$ \\
\hline \multirow[t]{2}{*}{ Ind-SE } & & & $-0.817 * * *$ & $-0.955 * * *$ \\
\hline & & & $(0.271)$ & $(0.249)$ \\
\hline \multirow[t]{2}{*}{ Ind-London } & & & $-0.968 * * *$ & $-1.102 * * *$ \\
\hline & & & $(0.280)$ & $(0.257)$ \\
\hline \multirow[t]{2}{*}{ Ind-RestUK } & & & $-0.896 * * *$ & $-0.997 * * *$ \\
\hline & & & $(0.277)$ & $(0.246)$ \\
\hline \multirow[t]{2}{*}{ Sector-Retail } & & & $-1.131 * * *$ & $-0.872 * * *$ \\
\hline & & & $(0.281)$ & $(0.252)$ \\
\hline \multirow[t]{2}{*}{ Sector-Office } & & & $-0.578 * *$ & $-0.704 * * *$ \\
\hline & & & $(0.257)$ & $(0.242)$ \\
\hline \multirow[t]{2}{*}{ Sector-Ind. } & & & $-0.853 * * *$ & $-0.973 * * *$ \\
\hline & & & $(0.274)$ & $(0.246)$ \\
\hline \multirow[t]{2}{*}{ Ret.SE+Ret.London } & & & $-0.529 * *$ & $-0.518 * *$ \\
\hline & & & $(0.255)$ & $(0.244)$ \\
\hline \multirow[t]{2}{*}{ Ret.SE+London+RestUK } & & & $-0.787 * * *$ & $-0.730 * * *$ \\
\hline & & & $(0.264)$ & $(0.247)$ \\
\hline \multirow[t]{2}{*}{ Office-SE-London } & & & -0.395 & $-0.419 *$ \\
\hline & & & $(0.249)$ & $(0.238)$ \\
\hline \multirow[t]{2}{*}{ Office-SE-London-RestUK } & & & $-0.578 * *$ & $-0.626 * * *$ \\
\hline & & & $(0.257)$ & (0.239) \\
\hline
\end{tabular}

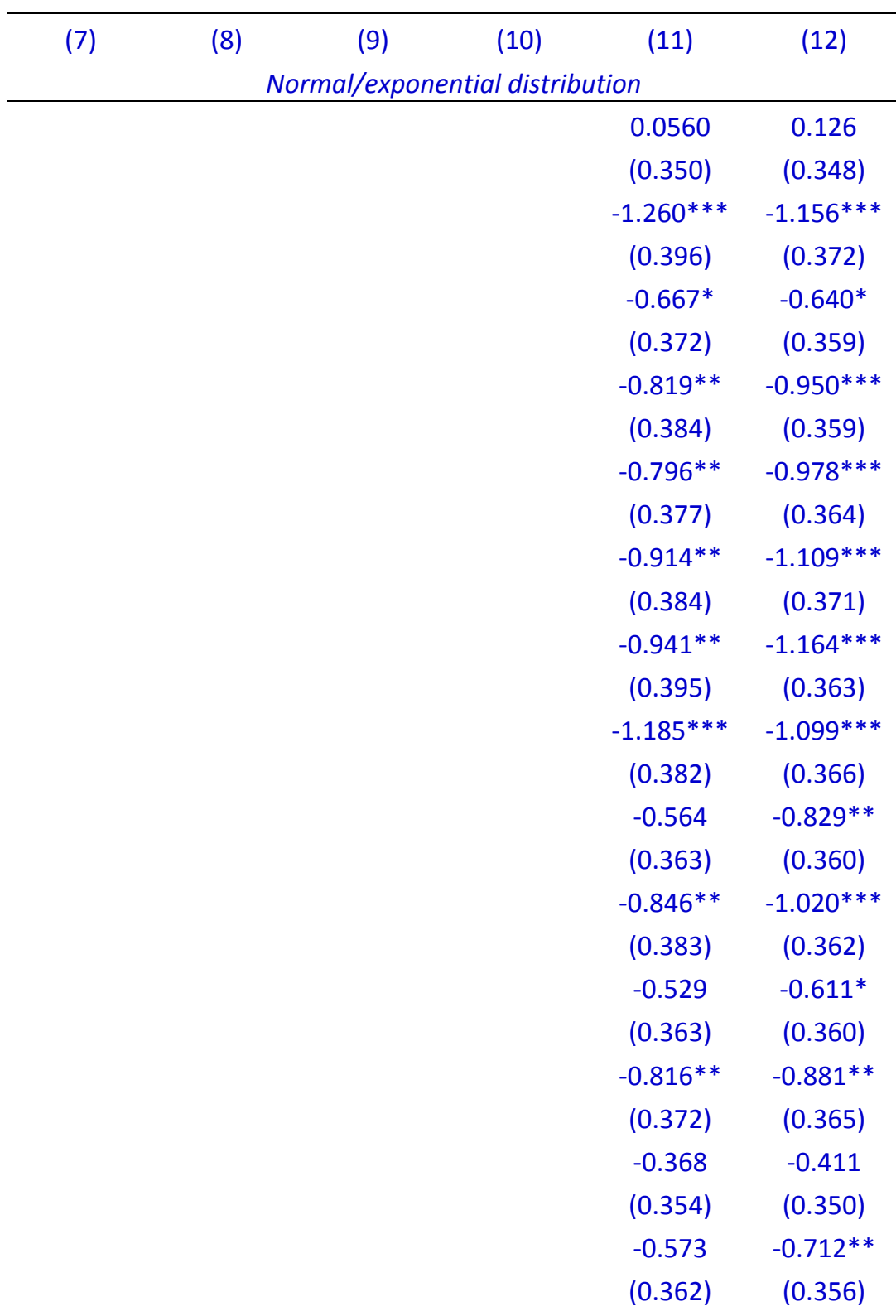




\begin{tabular}{|c|c|c|c|c|c|c|c|c|c|c|c|c|}
\hline \multirow[t]{2}{*}{ Inexret } & \multirow[t]{2}{*}{ (1) } & $(2)$ & $(3)$ & (4) & (5) & (6) & (7) & (8) & (9) & $(10)$ & $(11)$ & $(12)$ \\
\hline & & \multicolumn{5}{|c|}{ Normal/half-normal distribution } & \multicolumn{6}{|c|}{ Normal/exponential distribution } \\
\hline \multirow{2}{*}{\multicolumn{3}{|c|}{ Ind.-SE-London }} & & & $-0.922 * * *$ & $-1.030 * * *$ & & & & & $-0.896 * *$ & $-1.046 * * *$ \\
\hline & & & & & $(0.278)$ & $(0.253)$ & & & & & $(0.385)$ & $(0.367)$ \\
\hline \multirow{2}{*}{\multicolumn{3}{|c|}{ Ind.-SE-London-RestUK }} & & & $-0.984 * * *$ & $-1.068 * * *$ & & & & & $-0.982 * *$ & $-1.157^{* * *}$ \\
\hline & & & & & $(0.280)$ & $(0.250)$ & & & & & $(0.388)$ & $(0.366)$ \\
\hline \multirow{2}{*}{\multicolumn{3}{|c|}{ Sector-Retail+London }} & & & $-0.912 * * *$ & $-0.892 * * *$ & & & & & $-0.952 * *$ & $-1.121 * * *$ \\
\hline & & & & & $(0.269)$ & $(0.245)$ & & & & & $(0.373)$ & $(0.363)$ \\
\hline \multirow{2}{*}{\multicolumn{3}{|c|}{ Sector-retail+London+restUK }} & & & $-0.929 * * *$ & $-0.954 * * *$ & & & & & $-0.955^{* *}$ & $-1.144 * * *$ \\
\hline & & & & & $(0.272)$ & $(0.246)$ & & & & & $(0.377)$ & $(0.363)$ \\
\hline \multirow{2}{*}{\multicolumn{3}{|c|}{ GDP_growth }} & & & $-1.207 * * *$ & $-1.184 * * *$ & & & & & $-1.644 * * *$ & $-1.678 * * *$ \\
\hline & & & & & $(0.0572)$ & $(0.0500)$ & & & & & $(0.0826)$ & $(0.0776)$ \\
\hline \multirow[t]{2}{*}{ Constant } & $-2.920 * * *$ & $-2.939 * * *$ & $-2.915^{* * *}$ & $-3.277 * * *$ & $-2.360 * * *$ & $-2.729 * * *$ & $-4.048 * * *$ & $-4.075 * * *$ & $-4.056 * * *$ & $-4.695 * * *$ & $-3.185^{* * *}$ & $-3.661 * * *$ \\
\hline & -0.0404 & $(0.0407)$ & (0.0399) & $(0.0383)$ & $(0.170)$ & $(0.168)$ & $(0.0601)$ & $(0.0593)$ & $(0.0588)$ & $(0.0575)$ & $(0.245)$ & $(0.244)$ \\
\hline \multicolumn{13}{|l|}{ Vsigma } \\
\hline \multirow[t]{2}{*}{ Ingdp } & & & & $-3.867 * * *$ & & $-3.801 * * *$ & & & & $-4.025 * * *$ & & $-3.818 * * *$ \\
\hline & & & & $(0.182)$ & & $(0.148)$ & & & & $(0.131)$ & & $(0.121)$ \\
\hline \multirow[t]{2}{*}{ Constant } & $-5.842 * * *$ & $-5.823 * * *$ & $-6.144 * * *$ & $42.30 * * *$ & $-5.531 * * *$ & $41.49 * * *$ & $-5.524 * * *$ & $-5.539 * * *$ & $-5.687 * * *$ & $44.43 * * *$ & $-5.410 * * *$ & $41.83 * * *$ \\
\hline & $(0.101)$ & $(0.100)$ & $(0.123)$ & $(2.235)$ & $(0.0936)$ & $(1.819)$ & $(0.0728)$ & $(0.0699)$ & $(0.0756)$ & $(1.622)$ & $(0.0637)$ & $(1.495)$ \\
\hline \multicolumn{13}{|l|}{ Observatio } \\
\hline ns & 2,340 & 2,340 & 2,340 & 2,340 & 2,340 & 2,340 & 2,340 & 2,340 & 2,340 & 2,340 & 2,340 & 2,340 \\
\hline \multicolumn{13}{|c|}{ Standard errors in parentheses } \\
\hline \multicolumn{13}{|c|}{$* * * p<0.01, * * p<0.05, * p<0.1$} \\
\hline
\end{tabular}


Table 5: Portfolio specific efficiency scores based on Model 6, Table 4

\begin{tabular}{|c|c|c|c|c|c|c|c|c|c|c|c|}
\hline Portfolio/Year & 1987 & 1988 & 1989 & 1990 & 1991 & 1992 & 1993 & 1994 & 1995 & 1996 & 1997 \\
\hline Office-City & 0.93 & 0.93 & 0.9 & 0.73 & 0.59 & 0.73 & 0.93 & 0.87 & 0.86 & 0.87 & 0.9 \\
\hline Retail-SE & 0.96 & 0.96 & 0.93 & 0.86 & 0.87 & 0.88 & 0.94 & 0.94 & 0.89 & 0.92 & 0.94 \\
\hline Retail-London & 0.93 & 0.94 & 0.89 & 0.68 & 0.7 & 0.76 & 0.89 & 0.91 & 0.83 & 0.88 & 0.93 \\
\hline Retail-RestUK & 0.95 & 0.95 & 0.93 & 0.87 & 0.89 & 0.89 & 0.95 & 0.94 & 0.9 & 0.91 & 0.94 \\
\hline Office-SE & 0.94 & 0.95 & 0.93 & 0.83 & 0.82 & 0.82 & 0.94 & 0.92 & 0.88 & 0.9 & 0.93 \\
\hline Office-RestUK & 0.95 & 0.95 & 0.95 & 0.85 & 0.88 & 0.86 & 0.94 & 0.93 & 0.88 & 0.9 & 0.91 \\
\hline Ind-SE & 0.95 & 0.96 & 0.94 & 0.86 & 0.88 & 0.84 & 0.94 & 0.92 & 0.88 & 0.91 & 0.93 \\
\hline Ind-London & 0.95 & 0.96 & 0.94 & 0.84 & 0.9 & 0.86 & 0.95 & 0.93 & 0.89 & 0.92 & 0.93 \\
\hline Ind-RestUK & 0.95 & 0.96 & 0.94 & 0.87 & 0.91 & 0.9 & 0.95 & 0.94 & 0.88 & 0.91 & 0.92 \\
\hline Sector-Retail & 0.95 & 0.95 & 0.92 & 0.85 & 0.88 & 0.89 & 0.94 & 0.94 & 0.89 & 0.91 & 0.94 \\
\hline Sector-Office & 0.95 & 0.95 & 0.93 & 0.82 & 0.8 & 0.81 & 0.94 & 0.92 & 0.89 & 0.9 & 0.92 \\
\hline Sector-Ind. & 0.95 & 0.96 & 0.94 & 0.86 & 0.89 & 0.86 & 0.94 & 0.93 & 0.88 & 0.91 & 0.93 \\
\hline Ret.SE-Ret.London & 0.94 & 0.95 & 0.91 & 0.77 & 0.79 & 0.83 & 0.92 & 0.92 & 0.86 & 0.9 & 0.93 \\
\hline Ret.SE-London-RestUK & 0.95 & 0.95 & 0.92 & 0.81 & 0.83 & 0.86 & 0.93 & 0.93 & 0.88 & 0.91 & 0.94 \\
\hline Office-SE-London & 0.94 & 0.94 & 0.92 & 0.78 & 0.72 & 0.78 & 0.94 & 0.9 & 0.87 & 0.89 & 0.92 \\
\hline Office-SE-London-RestUK & 0.94 & 0.95 & 0.93 & 0.81 & 0.78 & 0.81 & 0.94 & 0.92 & 0.88 & 0.89 & 0.92 \\
\hline Ind.-SE-London & 0.95 & 0.96 & 0.94 & 0.85 & 0.89 & 0.85 & 0.94 & 0.93 & 0.89 & 0.91 & 0.93 \\
\hline Ind.-SE-London-RestUK & 0.95 & 0.96 & 0.94 & 0.86 & 0.9 & 0.87 & 0.95 & 0.93 & 0.89 & 0.91 & 0.93 \\
\hline Sector-Retail-London & 0.95 & 0.95 & 0.93 & 0.84 & 0.85 & 0.86 & 0.94 & 0.94 & 0.89 & 0.91 & 0.93 \\
\hline Sector-retail-London-restUK & 0.95 & 0.95 & 0.93 & 0.85 & 0.87 & 0.86 & 0.94 & 0.93 & 0.89 & 0.91 & 0.93 \\
\hline
\end{tabular}


Table 5: Portfolio specific efficiency scores based on Model 6, Table 4 (Cont'd)

\begin{tabular}{|c|c|c|c|c|c|c|c|c|c|c|}
\hline Portfolio/Year & 1998 & 1999 & 2000 & 2001 & 2002 & 2003 & 2004 & 2005 & 2006 & 2007 \\
\hline Office-City & 0.93 & 0.95 & 0.94 & 0.9 & 0.84 & 0.85 & 0.89 & 0.92 & 0.95 & 0.73 \\
\hline Retail-SE & 0.95 & 0.97 & 0.93 & 0.92 & 0.93 & 0.95 & 0.96 & 0.97 & 0.94 & 0.79 \\
\hline Retail-London & 0.9 & 0.94 & 0.86 & 0.84 & 0.89 & 0.9 & 0.94 & 0.95 & 0.89 & 0.69 \\
\hline Retail-RestUK & 0.94 & 0.97 & 0.92 & 0.91 & 0.94 & 0.96 & 0.97 & 0.95 & 0.95 & 0.77 \\
\hline Office-SE & 0.94 & 0.97 & 0.96 & 0.91 & 0.88 & 0.88 & 0.92 & 0.95 & 0.94 & 0.77 \\
\hline Office-RestUK & 0.94 & 0.97 & 0.96 & 0.93 & 0.92 & 0.94 & 0.94 & 0.95 & 0.96 & 0.76 \\
\hline Ind-SE & 0.95 & 0.97 & 0.96 & 0.92 & 0.92 & 0.93 & 0.93 & 0.95 & 0.95 & 0.78 \\
\hline Ind-London & 0.95 & 0.97 & 0.96 & 0.92 & 0.92 & 0.93 & 0.94 & 0.96 & 0.95 & 0.81 \\
\hline Ind-RestUK & 0.94 & 0.97 & 0.95 & 0.93 & 0.92 & 0.94 & 0.94 & 0.94 & 0.94 & 0.77 \\
\hline Sector-Retail & 0.94 & 0.97 & 0.94 & 0.91 & 0.93 & 0.95 & 0.95 & 0.95 & 0.93 & 0.76 \\
\hline Sector-Office & 0.94 & 0.97 & 0.96 & 0.92 & 0.89 & 0.89 & 0.92 & 0.95 & 0.96 & 0.78 \\
\hline Sector-Ind. & 0.94 & 0.97 & 0.96 & 0.92 & 0.91 & 0.93 & 0.93 & 0.95 & 0.95 & 0.77 \\
\hline Ret.SE-Ret.London & 0.93 & 0.96 & 0.9 & 0.88 & 0.92 & 0.93 & 0.96 & 0.96 & 0.92 & 0.74 \\
\hline Ret.SE-London-RestUK & 0.94 & 0.96 & 0.91 & 0.89 & 0.93 & 0.95 & 0.96 & 0.96 & 0.93 & 0.75 \\
\hline Office-SE-London & 0.94 & 0.96 & 0.95 & 0.91 & 0.86 & 0.87 & 0.91 & 0.94 & 0.95 & 0.75 \\
\hline Office-SE-London-RestUK & 0.94 & 0.97 & 0.95 & 0.92 & 0.89 & 0.9 & 0.92 & 0.95 & 0.96 & 0.76 \\
\hline Ind.-SE-London & 0.95 & 0.97 & 0.95 & 0.91 & 0.91 & 0.93 & 0.93 & 0.95 & 0.94 & 0.79 \\
\hline Ind.-SE-London-RestUK & 0.95 & 0.97 & 0.96 & 0.92 & 0.92 & 0.93 & 0.94 & 0.95 & 0.95 & 0.79 \\
\hline Sector-Retail-London & 0.94 & 0.97 & 0.95 & 0.92 & 0.92 & 0.93 & 0.94 & 0.95 & 0.95 & 0.77 \\
\hline Sector-retail-London-restUK & 0.94 & 0.97 & 0.95 & 0.92 & 0.92 & 0.93 & 0.94 & 0.95 & 0.95 & 0.77 \\
\hline
\end{tabular}


Table 5: Portfolio specific efficiency scores based on Model 6, Table 4 (Cont'd)

\begin{tabular}{|c|c|c|c|c|c|c|c|c|c|c|}
\hline Portfolio/Year & 2008 & 2009 & 2010 & 2011 & 2012 & 2013 & 2014 & 2015 & 2016 & Average \\
\hline Office-City & 0.59 & 0.79 & 0.94 & 0.92 & 0.93 & 0.96 & 0.96 & 0.96 & 0.88 & 0.87 \\
\hline Retail-SE & 0.69 & 0.87 & 0.94 & 0.93 & 0.96 & 0.97 & 0.95 & 0.96 & 0.88 & 0.92 \\
\hline Retail-London & 0.5 & 0.78 & 0.9 & 0.86 & 0.87 & 0.92 & 0.93 & 0.91 & 0.78 & 0.85 \\
\hline Retail-RestUK & 0.67 & 0.84 & 0.93 & 0.93 & 0.94 & 0.95 & 0.94 & 0.95 & 0.89 & 0.91 \\
\hline Office-SE & 0.66 & 0.81 & 0.9 & 0.9 & 0.92 & 0.98 & 0.97 & 0.96 & 0.88 & 0.90 \\
\hline Office-RestUK & 0.66 & 0.83 & 0.9 & 0.9 & 0.91 & 0.96 & 0.96 & 0.96 & 0.88 & 0.91 \\
\hline Ind-SE & 0.65 & 0.84 & 0.91 & 0.91 & 0.94 & 0.98 & 0.97 & 0.96 & 0.89 & 0.91 \\
\hline Ind-London & 0.65 & 0.84 & 0.91 & 0.91 & 0.95 & 0.97 & 0.96 & 0.96 & 0.89 & 0.91 \\
\hline Ind-RestUK & 0.66 & 0.84 & 0.91 & 0.91 & 0.94 & 0.97 & 0.97 & 0.96 & 0.89 & 0.91 \\
\hline Sector-Retail & 0.63 & 0.82 & 0.93 & 0.92 & 0.92 & 0.95 & 0.94 & 0.95 & 0.87 & 0.91 \\
\hline Sector-Office & 0.63 & 0.81 & 0.93 & 0.92 & 0.95 & 0.97 & 0.97 & 0.96 & 0.88 & 0.90 \\
\hline Sector-Ind. & 0.66 & 0.84 & 0.91 & 0.91 & 0.94 & 0.98 & 0.97 & 0.97 & 0.89 & 0.91 \\
\hline Ret.SE-Ret.London & 0.59 & 0.82 & 0.93 & 0.9 & 0.91 & 0.95 & 0.95 & 0.94 & 0.83 & 0.89 \\
\hline Ret.SE-London-RestUK & 0.62 & 0.83 & 0.93 & 0.91 & 0.92 & 0.95 & 0.95 & 0.94 & 0.86 & 0.90 \\
\hline Office-SE-London & 0.63 & 0.8 & 0.92 & 0.92 & 0.93 & 0.97 & 0.97 & 0.96 & 0.89 & 0.89 \\
\hline Office-SE-London-RestUK & 0.64 & 0.82 & 0.92 & 0.92 & 0.93 & 0.97 & 0.97 & 0.97 & 0.89 & 0.90 \\
\hline Ind.-SE-London & 0.65 & 0.84 & 0.91 & 0.91 & 0.94 & 0.98 & 0.97 & 0.97 & 0.89 & 0.91 \\
\hline Ind.-SE-London-RestUK & 0.66 & 0.84 & 0.91 & 0.91 & 0.94 & 0.98 & 0.97 & 0.97 & 0.89 & 0.91 \\
\hline Sector-Retail-London & 0.64 & 0.82 & 0.94 & 0.92 & 0.94 & 0.97 & 0.96 & 0.96 & 0.88 & 0.91 \\
\hline Sector-retail-London-restUK & 0.64 & 0.83 & 0.93 & 0.92 & 0.94 & 0.97 & 0.96 & 0.96 & 0.89 & 0.91 \\
\hline
\end{tabular}


Table 6: Evolution of portfolio specific efficiencies (based on Model 7, Table 3)

\begin{tabular}{lccc}
\hline Portfolio & $1987-1989$ & $2014-2016$ & $(2014-2016) /(1987-1989)$ \\
\hline Office-City & 0.92 & 0.93 & 1.01 \\
Retail-SE & 0.95 & 0.93 & 0.98 \\
Retail-London & 0.92 & 0.87 & 0.95 \\
Retail-RestUK & 0.94 & 0.93 & 0.98 \\
Office-SE & 0.94 & 0.94 & 1.00 \\
Office-RestUK & 0.95 & 0.93 & 0.98 \\
Ind-SE & 0.95 & 0.94 & 0.99 \\
Ind-London & 0.95 & 0.94 & 0.99 \\
Ind-RestUK & 0.95 & 0.94 & 0.99 \\
Sector-Retail & 0.94 & 0.92 & 0.98 \\
Sector-Office & 0.94 & 0.94 & 0.99 \\
Sector-Ind. & 0.95 & 0.94 & 0.99 \\
Ret.SE-Ret.London & 0.93 & 0.91 & 0.97 \\
Ret.SE-London-RestUK & 0.94 & 0.92 & 0.98 \\
Office-SE-London & 0.93 & 0.94 & 1.01 \\
Office-SE-London-RestUK & 0.94 & 0.94 & 1.00 \\
Ind.-SE-London & 0.95 & 0.94 & 0.99 \\
Ind.-SE-London-RestUK & 0.95 & 0.94 & 0.99 \\
Sector-Retail-London & 0.94 & 0.93 & 0.99 \\
Sector-retail-London-restUK & 0.94 & 0.94 & 0.99 \\
\hline
\end{tabular}


Table 7: 6 year annual average portfolio efficiencies (based on Model 6, Table 4)

\begin{tabular}{lccccc}
\hline Portfolio & $1987-1992$ & $1993-1998$ & $1999-2004$ & $2005-2010$ & $2011-2016$ \\
\hline Office-City & 0.80 & 0.89 & 0.90 & 0.82 & 0.94 \\
Retail-SE & 0.91 & 0.93 & 0.94 & 0.87 & 0.94 \\
Retail-London & 0.82 & 0.89 & 0.90 & 0.79 & 0.88 \\
Retail-RestUK & 0.91 & 0.93 & 0.95 & 0.85 & 0.93 \\
Office-SE & 0.88 & 0.92 & 0.92 & 0.84 & 0.94 \\
Office-RestUK & 0.91 & 0.92 & 0.94 & 0.84 & 0.93 \\
Ind-SE & 0.91 & 0.92 & 0.94 & 0.85 & 0.94 \\
Ind-London & 0.91 & 0.93 & 0.94 & 0.85 & 0.94 \\
Ind-RestUK & 0.92 & 0.92 & 0.94 & 0.84 & 0.94 \\
Sector-Retail & 0.91 & 0.93 & 0.94 & 0.84 & 0.93 \\
Sector-Office & 0.88 & 0.92 & 0.93 & 0.84 & 0.94 \\
Sector-Ind. & 0.91 & 0.92 & 0.94 & 0.85 & 0.94 \\
Ret.SE-Ret.London & 0.87 & 0.91 & 0.93 & 0.83 & 0.91 \\
Ret.SE-London-RestUK & 0.89 & 0.92 & 0.93 & 0.84 & 0.92 \\
Office-SE-London & 0.85 & 0.91 & 0.91 & 0.83 & 0.94 \\
Office-SE-London-RestUK & 0.87 & 0.92 & 0.93 & 0.84 & 0.94 \\
Ind.-SE-London & 0.91 & 0.93 & 0.93 & 0.85 & 0.94 \\
Ind.-SE-London-RestUK & 0.91 & 0.93 & 0.94 & 0.85 & 0.94 \\
Sector-Retail-London & 0.90 & 0.93 & 0.94 & 0.85 & 0.94 \\
Sector-retail-London-restUK & 0.90 & 0.92 & 0.94 & 0.85 & 0.94 \\
\hline
\end{tabular}

